\title{
PSEUDO-SYMMETRIC MODULAR DIOPHANTINE INEQUALITIES
}

\author{
J. C. Rosales
}

Abstract. In this paper we study and characterize those Diophantine inequalities $a x \bmod b \leqslant x$ whose set of solutions is a pseudo-symmetric numerical semigroup.

Mathematics subject classification (2000): 20M14,s 13H10.

Key words and phrases: numerical semigroups, symmetric, pseudo-symmetric, modular Diophantine inequalities, Frobenius number.

\section{REFERENCES}

[1] R. APÉRY, Sur les branches superlinéaires des courbes algébriques, C. R. Acad. Sci. Paris, 222, (1946).

[2] V. Barucci, D. E. DobBs AND M. Fontana, Maximality Properties in Numerical Semigroups and Applications to One-Dimensional Analytically Irreducible Local Domains, Memoirs of the Amer. Math. Soc.. 598, (1997).

[3] R. Fröberg, G. Gottlieb And R. HÄGgkvist, On numerical semigroups, Semigroup Forum, 35, (1987), 63-83.

[4] J. HERZOG, Generators and relations of abelian semigroups and semigroup rings, Manuscripta Math., 3, (1970), 175-193.

[5] J. C. RosAles, M. B. BRANCO, Irreducible numerical semigroups, Pacific J. Math. 209, (2003), $131-143$.

[6] J. C. Rosales, Symmetric modular Diophantine inequalities, to appear in Proc. Amer. Math. Soc.

[7] J. C. Rosales, P. A. GARcíA-SÁnCHEZ, Finitely generated commutative monoids, Nova Science Publishers, New York, 1999.

[8] J. C. RosAlES, P. A. GARCÍA-SÁNCHEZ, Every positive integer is the Frobenius number of an irreducible numerical semigroup with at most four generators, Arkiv Mat., 42, (2004), 301-306.

[9] J. C. Rosales, P. A. GARcÍA-SÁncheZ And J. I. GarcíA-GARCÍA, Every positive integers is the Frobenius number of a numerical semigroup with three generators, Math. Scandinavica., 94, (2004), $5-12$.

[10] J. C. Rosales, P. A. García-Sánchez, J. I. García-García and J. M. Urbano-Blanco, Proportionally modular Diophantine inequalities, J. Number Theory, 103, (2003), 281-294.

[11] J. C. Rosales, P. A. García-SÁnchez and J. M. URbano-Blanco, Modular Diophantine inequalities and numerical semigroups, Pacific J. Math. 218 (2005), 379-398. 